\title{
Correction to: Common metabolic networks contribute to carbon sink strength of sorghum internodes: implications for bioenergy improvement
}

Yin $\mathrm{Li}^{1^{*}} \mathbb{D}$, Min Tu${ }^{1}$, Yaping Feng ${ }^{1}$, Wenqin Wang ${ }^{2}$ and Joachim Messing ${ }^{1^{*}}$

\section{Correction to: Biotechnol Biofuels (2019) 12:274}

https://doi.org/10.1186/s13068-019-1612-7

The original version of the article [1] unfortunately contained a mistake in author's first name. The name of the author has been corrected from Wenqing Wang to Wenqin Wang in this correction article. The original article [1] has been corrected.

\section{Author details}

${ }^{1}$ Waksman Institute of Microbiology, Rutgers, The State University of New Jersey, Piscataway, NJ 08854, USA. ${ }^{2}$ School of Agriculture and Biology, Shanghai Jiao Tong University, 800 Dong Chuan Road, Shanghai 200240, China.

Received: 21 May 2019 Accepted: 9 November 2019

Published online: 11 December 2019

\section{Reference}

1. Li Y, Tu M, Feng Y, Wang W, Messing J. Common metabolic networks contribute to carbon sink strength of sorghum internodes: implications for bioenergy improvement. Biotechnol Biofuels. 2019;12:274. https://doi. org/10.1186/s13068-019-1612-7.

\section{Publisher's Note}

Springer Nature remains neutral with regard to jurisdictional claims in published maps and institutional affiliations. 